\title{
The Implications of Enterprise-wide Pipeline Management Tools for Organizational Relations and Exchanges
}

\author{
Melissa Cefkin \\ IBM Almaden Research Center \\ 650 Harry Road \\ San Jose, CA 95120 \\ mcefkin@us.ibm.com
}

\author{
Jakita Owensby Thomas \\ IBM Almaden Research Center \\ 650 Harry Road \\ San Jose, CA 95120 \\ owensby@us.ibm.com
}

\author{
Jeanette Blomberg \\ IBM Almaden Research Center \\ 650 Harry Road \\ San Jose, CA 95120 \\ jblomberg@almaden.ibm.com
}

\begin{abstract}
This paper explores the impact of enterprise-wide processes and technologies on group relations and exchanges. We examine the use of Customer Relationship Management (CRM) tools in sales pipeline management. Through an ethnographic study of globallydistributed sales teams we show that the way enterprise-wide tools are integrated into daily practices impacts organizational relations and exchange. We pay particular attention to information exchange as a vehicle for building, leveraging and deterring organizational relations. Our analysis suggests that different approaches to using standardized tools and processes have variable impact on team relations. We provide support for the argument that technologies should be designed and deployed in accordance with an understanding of the contexts of use and in consideration for their impact on organizational relations.
\end{abstract}

Categories and Subject Descriptors: H5.m. Information interfaces and presentation (e.g., HCI): Miscellaneous.

General Terms: Management, Design, Standardization

Keywords: Work practices, information exchange, enterprisewide technologies, business processes, sales operations, organizational relations, ethnography.

\section{INTRODUCTION}

For large organizations with sales professionals spread across various locations and interacting with numerous individuals throughout the client organization, effective information exchange and collaboration is critical to the success of sales teams. Team members must work together to gather, assemble and make sense of information; create and design solutions; and efficiently and effectively respond to customers' expectations. In an effort to provide a single "face" to the customer, they must coordinate and work in concert in developing and managing customer relationships. This requires that each division, product group, and individual seller know enough about what the other is doing to be able to avoid missteps and misrepresentation, and ideally leverage their collective efforts towards greater value.

Managing actions related to specific sales opportunities that exist at any given time across divisions, geographies and brands is a critical part of the effort to present a consistent and coherent view of activities to the customer. Toward that end, sellers across the

Permission to make digital or hard copies of all or part of this work for personal or classroom use is granted without fee provided that copies are not made or distributed for profit or commercial advantage and that copies bear this notice and the full citation on the first page. To copy otherwise, or republish, to post on servers or to redistribute to lists, requires prior specific permission and/or a fee.

GROUP'07, November 4-7, 2007, Sanibel Island, Florida, USA.

Copyright 2007 ACM 978-1-59593-845-9/07/0011_..\$5.00. team must maintain, track and share information on their sales opportunities in a way that provides meaningful insight on the current state of their efforts. Many companies use Customer Relationship Management (CRM) tools and an attendant set of processes, as part of this effort. CRM tools allow for the tracking of information related to potential sales opportunities such as the products or services under consideration the potential amount of the sale, and the likelihood of winning the sale [6]. It is expected that the consistent use of CRM tools as a means of capturing and sharing information about sales opportunities across the organization will result in greater transparency and will support the ability to make timely decisions and act upon the information at hand.

The use of CRM tools is consistent with attempts of organizations to gain control over their operations by requiring that employees use standard tools. The use of standard tools is assumed and expected to compel particular behaviors. For example, if sellers are mandated to enter certain information into required fields in the tool, this will ensure that they acquire, update and track this information.

Furthermore, a common view holds that standardized processes are the most effective way to engage with standardized tools. As such, it is often recommended that sellers enter data into the tool at specified intervals or when triggered by specific events (e.g. an opportunity over $\$ 1$ million dollars). It is argued that standardization helps reduce costs, simplify decision making, increase effectiveness of information sharing, and enhance innovation $[5,8,17,20]$. However, little attention is paid to the consequences of such a regime on the everyday working practices of and relations among team members.

Others have shown that how technology is enacted in practice shapes the impact it has on organizational performance $[3,11,12$, 13]. Technology does not have a singular, deterministic relation to the activities in which it participates, but instead the impact is shaped and mediated by the particular ways the technology is integrated into day to day practices $[4,9,14,16,18]$. In particular they suggest that organizational, historical, and individual and group expertise factors contribute to the impact technology has on practice.

Dourish [7], in an examination of workflow technologies as a particular instance of standardized tools and processes, suggests workflow technologies not only have the role of supporting coordination of work, but also operate as organizational accounting devices to signal that particular kinds of work are getting done. In many ways the CRM tool is a quintessential organizational accounting device as it is used to signal the overall forecast of the organization's business performance. While Dourish repeats the critiques levied by those who show the potentially harmful role of workflow technologies on work group practices, he does not explore specifically how workflow 
technologies as organizational accounting devices impact work group dynamics and relational practices. Sharing with Barley [1] in the view that technologies can serve as occasions that prompt configurations or reconfigurations of social dynamics, our focus in this paper is on how the particular use of CRM tools and attendant processes shapes and reveals aspects of intra-team relations and accountability.

Drawing on an ethnographic study of the use of CRM tools and processes to support the sales opportunity (pipeline) management in a large, multi-national corporation, we explore variations in the ways these tools have been taken up in practice and the impact this has on organizational relations and exchange.

\section{STUDY BACKGROUND AND METHODOLOGY}

The authors have been involved in a number of ethnographic studies of work practices of sales professionals and teams. Here we focus particularly on a study of three globally-distributed sales teams of a large IT product and services company undertaken from fall of 2004 to spring of 2006. Each team had over 60 members located on three or more continents and each was dedicated to a single global customer. The design of the corporate sales coverage model meant that each sales team was composed of representatives from many of the company's divisions including the different brands, products and services offered. The teams were distributed geographically in order to align with the customer's global operations. The ability to exchange information across the brands, divisions and geographies and otherwise build and maintain coordinated and shared understandings of information and group activities was critical for the overall success for the team and the enterprise.

The CRM tool and processes related to sales pipeline management served as one occasion for the exchange of information and the establishment and maintenance of relationships. Use of the CRM tool by the sales organization was mandated by the company. The particular CRM tool in use at the company was a customized implementation of a large, well known package solution. The host organization had designed the processes that would accompany the use of the tool. In particular, the company expected the sellers to keep track of the status of sales opportunities using this tool and to participate in the weekly conference calls to discuss the team's sales opportunities. (Product specialists and others are sometimes asked to join pipeline calls for their divisions instead of or in addition to the calls for teams supporting a single client. Similarly management participated in multiple pipeline calls as they were responsible for taking the pipeline information from their team call into a meeting with their own divisional management).

Information on the use of the tool was available on the corporate intranet where sales team members gained access to the particular processes designed to support the use of the tool. More importantly the sales teams were told how use of the CRM tool was related to the overall methodology and selling approach advanced by the corporation. The view was that through use of the CRM tool information would be exchanged and sales teams would be able to keep abreast of opportunities in the pipeline.

Our research of the three distributed sales teams took place consecutively, with each team studied for a three to five month period. The teams were selected based on broader project objectives. $^{1}$ Our ethnographic study consisted of three primary data gathering activities: observations, interviews, and examination of artifacts. The observations consisted of face-toface participant observation in various team activities such as account planning sessions, status meetings and regular daily interactions accessed through the shadowing of select members of the teams as they went about their work. We also regularly "observed" various team and sub-team level conference calls through which all the teams regularly performed their work. We conducted open-ended, semi-structured interviews each approximately one hour in length of select team members both in person and by phone. The interviews were recorded, with participant consent, and logged with portions of the interviews transcribed for later analysis.

Interview participants were selected based on their roles (e.g., client manager, product specialist, controller), tenure, extent of dedication to the account (e.g., fulltime or part-time while supporting other accounts as well) and geographical locations. We interviewed participants regarding their sales pipeline management activities and observed regularly scheduled conference calls where sales pipeline information was discussed. We also collected and examined documents shared across the team related to this activity as well as reviewed material provided through the corporate website about the CRM tool and the approach to the tool and practices encouraged by the company. In total we conducted 41 interviews and engaged in 165 hours of observation.

We adopted an ethnographic approach to allow access to the subtle and dynamic aspects of individual and collective work practices and to gain a view onto the broader social context and the practices of meaning making and relationship formation in which members of these teams engaged. By including both ethnographic observations and interviews we were able to gain an understanding of how people participating in the work of sales thought about and organized themselves in relation to selling activities and how they oriented to the tool and processes designed to support their work. It also provided us with insight into relationships between information exchange embedded in the sales pipeline management process and the broader work context of sales professionals through which organizational relations are formed and maintained.

\section{FINDINGS}

A range of approaches to managing the sales pipeline and responding to the company-wide mandate to use the CRM tool were observed. As a way to reveal some of the relevant differences, we describe two contrasting approaches to pipeline management and CRM tool usage. These two approaches represent two ends of a continuum in regards to the extent that individual team members were required to interact with the CRM tool through standard processes. We show that the approach to CRM tool use and processes had implications for information exchange and organizational relations within the teams.

Five key dimensions can be used to differentiate approaches to pipeline management and CRM tool use. These are: (1) recording pipeline information, (2) roles and responsibilities for managing

\footnotetext{
${ }^{1}$ This study was part of a broader action-research project about team collaboration done in conjunction with members of the corporate learning division of the company.
} 
pipeline information, (3) dissemination of pipeline information, (4) artifacts used in reviewing the pipeline, and (5) focus of the pipeline reviews. Two contrasting approaches that we name the Do-it-Alike approach and the Do-it-as-You-Like are highlighted here and are reflective of approaches taken by two of the three teams in our study. The two contrasting approaches are characterized below according to the five key dimensions. We then provide a description of the practices and relational dynamics that characterized the two teams who evidenced these contrasting approaches to pipeline management.

\section{The Do-it-Alike Approach}

In the Do-it-Alike approach there is an emphasis on uniformity and standardization in practices.

\section{Recording pipeline information}

Information is recorded directly into the CRM tool by each member of the team. Everyone is responsible for interacting with the tool and populating the tool with the required pipeline information.

\section{Roles and responsibilities for managing pipeline information}

While all team members are ultimately responsible for their pipeline entries, a person can be assigned the role of coordinating with members of the sales team to ensure that updates have been made in the CRM tool. In some cases, this person might have to take it upon themselves to obtain the necessary information to complete the updates for other members of the team. However, each seller is accountable for the information entered in the tool. In addition, the sellers who are responsible for opportunities that include the bundling of software, hardware and services must make sure product specialists update their entries so the pipeline record for the opportunity is complete.

\section{Dissemination of pipeline information within the team}

Sales pipeline data is provided to the team's general manager and controller through reports generated by the tool. The team has access to pipeline information by directly querying the tool and also through pipeline reports. Management closely tracks pipeline information as recorded in the tool from week to week.

\section{Artifacts used in reviewing the pipeline}

A report is generated by the CRM tool showing a comprehensive set of opportunities that are being pursued across the team. This report is used as the key artifact of review during weekly sales pipeline meetings. While individual sellers may produce their own views onto the pipeline, this is the document referred to in pipeline meetings and for which the sellers are held accountable. A total (e.g., flood-light) view onto the comprehensive set of existing opportunities is made available to the team through this document.

\section{Focus of the pipeline reviews}

The focus of the weekly pipeline is on the CRM tool, on its use and on the information it contains. There is an emphasis on process completion. For example, the focus is on whether everyone entered and updated their opportunity data. During the meeting sellers are questioned about the thoroughness of the information in the CRM tool. For example, they are queried as to whether there any known opportunities not yet reflected in the CRM tool or if any revenue amounts or potential close dates have changed.
The Do-it-Alike approach was manifested most directly by one of the three teams we studied. This team had 79 members at the time of our study. They aimed to operate in a highly coordinated fashion. Senior management on the team (e.g., the team's general manager and controller) required that pipeline information be updated directly into the CRM system. Thus individual team members updated data on the sales opportunities for which they were responsible. Client managers, who ultimately "owned" particular opportunities that spanned product lines, had to spend time coordinating with the brand specialists to ensure that they entered and updated information on a weekly basis for their particular component of the overall opportunity. This coordination effort demanded heavy use of phone, email and instant messaging to make requests for information or to follow up on the data entered. This in turn required that individuals spend time interpreting and clarifying the information currently in the tool in order to determine whether it was complete, to understand the implications of any changes made and to determine how best to enter new information (e.g., where exactly it should go and how it should be recorded).

A sales team assistant was enrolled to help ensure sufficient updating and completion of the team's sales pipeline data in the system. The assistant estimated that she spent $50 \%$ of her time attending to the process. This involved monitoring changes, determining what still needed to be updated, tracking down members of the sales team to request their participation in updating the information into the system (or in some cases assuming responsibility for doing so herself), communicating with senior management around key actions and status, and preparing reports for the weekly sales opportunity review meetings.

Despite these concerted efforts, information in the system did at times lag or would otherwise remain incomplete or insufficient. ${ }^{2}$ Conversations about the pipeline, both informally in the course of the work and during the weekly pipeline review were occasions for providing some of that missing information.

The weekly team meeting to discuss the status of the pipeline was conducted as a conference call and timed to allow world-wide participation. The team that most exemplified the Do-it-Alike approach spent considerable time during this review meeting sorting out what data had been entered into the system and trying to understand what changes had occurred since the prior week and the reasons for the changes. For instance, a lengthy discussion might focus on clarifying whether a new opportunity entered in the pipeline was an off-shoot of a previously existing one, and thus whether the projected revenue for the other opportunity had been adjusted accordingly, or if it was a net new opportunity. While a good deal of time was spent making sure the data in the CRM tool was "correct", the meeting also provided the occasion

\footnotetext{
${ }^{2}$ Some information lags and inaccuracies were the result of sellers' efforts to better control their work by manipulating the data in the system. Concerns for the implications of making data visible and public, as have been identified by Orlikowski [15], were among these. For instance, sellers might manage dates in attempt to have the pipeline line-up according to their incentive and quota systems. Or they might split apart a single large opportunity into several small ones so as to avoid triggering extra attention to their efforts by their manager or others: the larger an opportunity the more likely additional managers up the hierarchy would become aware of the opportunity and offer "help", often experienced by sellers as needing to manage additional coordination requirements and as the exertion of pressure to close the deal.
} 
for team members to get an overview of opportunities in the pipeline and to coordinate their activities and identify ways in which they might be able to advance opportunities together.

A significant amount of the communication and collaboration efforts of this team was directed towards fulfilling the CRM process. Many of their interactions were aimed towards ensuring that the information required by the CRM tool was complete. For the client managers, in particular, this meant that they spent a fair amount of their time "chasing down" team members in an effort to make sure the required information had been entered in the tool. They often found themselves having to follow up repeatedly with individuals when information wasn't readily provided. In turn, their team mates might anticipate that being contacted by a client manager might have to do with requests for the information. We observed instances in which the initial response upon being contacted by a client manager was defensiveness, confessing to their tardiness or explaining reasons for why updated information was unavailable.

Concerns that conversations aimed at discussing joint interests in the client account risk turning into pipeline review style meetings (which are deemed of marginal value by sellers in actually advancing their sales efforts) is evidenced in the following exchange: A sales team manager, a client manager and a brand specialist are meeting to discuss current opportunities and to identify key focus areas for their collective attention. As they begin to wrap up the discussion, the sales team manager (who is based in Europe) remarks to the New York based specialist "last year we had regular calls [to collaborate on opportunities]. Maybe we should have regular calls every four to six weeks?" Here the specialist responds assertively, reminding him "you're not my only team!" (indicating that she serves other accounts as well) and stating firmly "I'm not going to agree to any more calls." The list of calls already on the calendar with the explicit purpose of keeping everyone up-to-date are recalled and it is stressed by the client manager that "we are trying not to make it [this particular exchange] a [name used for pipeline review meeting] call."

On this team, the tenor of the weekly pipeline review meeting was guided by an orientation to sorting out the existing data recorded in the tool and debating which categories should be used in classifying the data. The discussion commonly revolved around where to place pipeline information according to the categories required of the tool, with sellers having to justify why they categorized their opportunities in a particular way. For instance, changes either up or down in the 'likelihood' of sale would be discussed in terms of whether the opportunity was being reflected "correctly" in the tool and what the implications would be for either under or over representing the sales probability. The orientation was largely on correcting and perfecting the status of the information in the tool.

Categorization of the information into one box or another or changing the exact record also resulted in the potential for disagreement or tension among participants. In one instance, for example, it was brought to the attention of the general manager that an entry had been entered in error; instead of a total potential revenue amount in the thousands, the opportunity was in fact worth millions. In addition, the opportunity was not yet marked "qualified", meaning they had not factored it into potential quarterly revenue. While this resulted in great excitement on behalf of the manager (as this change would signal their being closer to potentially reaching their quarterly and yearly target), the ensuing discussion raised consternation for the seller. The manager wanted to reclassify the opportunity as "validated". The seller replied quickly that if they did so, he would request that the total revenue potential be lowered. The implication to the seller was that he would likely receive greater attention and pressure than perhaps he felt would be useful. The manager disagreed, despite the sellers protestations. The final choice in where to locate the information inside the tool had the strong likelihood of initiating a chain reaction of additional activities occurring in response.

\section{The Do-it-as-You-Like Approach}

The approach we are calling the Do-it-as-You-Like approach was characterized by variation in how the team interacted with the CRM tool and how they recorded and managed their pipeline.

\section{Recording pipeline information}

Information about the pipeline is tracked and recorded by members of the team in a variety of ways. Each team member is allowed to use whatever tools and processes work best, including spreadsheets, logs, etc. Individual team members are not required to interact directly with the CRM tool except as they deem it valuable.

\section{Roles and responsibilities for managing pipeline information}

Client managers responsible for particular products and services (e.g., IT services) take it upon themselves to understand the status of current opportunities and any issues that might impact advancing these opportunities. They are not responsible for ensuring data entry into the CRM system by themselves or other sellers.

\section{Dissemination of pipeline information within the team}

Sales managers also must be able to accurately reflect the status of key opportunities to the team's general manager and controller, and for disseminating information to team management on a weekly basis or as required. They are not required to use the CRM tool for this purpose.

\section{Artifacts used in reviewing the pipeline}

The overall view onto sales opportunities is maintained according to tools and processes preferred by the account management. Pipeline data are updated regularly into the CRM tool by these individuals. A report is run using management's preferred tool and shared with team members in advance of the weekly pipeline review meeting. This report is only loosely used as an artifact for pipeline review during the regular review meetings.

\section{Focus of the pipeline reviews}

The focus of the pipeline review is on current activities and the state of active opportunities or, as relevant, on longer term strategic initiatives. Information deemed of particular relevance to understanding what actions need to be taken and how best to coordinate activities is at the center of the discussion. Only significant additions, changes or deletions to the pipeline database are discussed, and attention is focused on particular opportunities (e.g., a spotlight view).

This Do-it-as-You-Like approach was embodied most directly by a globally distributed team consisting of 70 members located in three main geographic regions. This team operated in a highly flexible and individually accommodating fashion. Each member of the team managed the sales opportunities they were responsible for in a manner of their own choosing. For example, some tracked and organized their efforts by email while others used a personally 
designed spreadsheet. There was no effort to enforce a particular way of maintaining and updating pipeline information, nor was each individual required to enter data directly into the CRM tool. Rather, team members worked out together with the client managers and each other what was acceptable and expected. The client managers often received updates during weekly meetings with the sellers supporting their area of the business. These meetings were often paired with other discussions and coaching. In other cases, sellers, brand specialists and client managers stayed current on the status of opportunities more informally through interactions that occurred for other reasons or through informal updates that took place throughout the week. These variations based on personal preferences and practices persisted throughout the management chain up to the general manager and controller. Pipeline information was supplied to them in a way chosen by the client managers.

A master view of the pipeline was held by general manager and controller and updated and maintained through various means: through written communications from the sellers or sales managers; through weekly sales team meetings where opportunity status was updated in real time; and through on-going interactions between team members and general manager. The controller and general manager worked together weekly to ensure that they had a sufficient picture as to the current status so as to be able to lead a meaningful and effective pipeline review meeting focused on where and how the team should strive to make impact.

Pipeline information was only updated consistently in the CRM tool once it reached the level of the general manager and controller. On a monthly basis the general manager and controller reviewed the pipeline data at a greater level of granularity, aligning and correcting the data as reflected in the CRM tool.

The fact that there was no effort to enforce a uniform way of tracking pipeline data within the team meant that little, if any, interaction time was diverted to the task of CRM process completion. During the weekly review calls, little to no time was spent updating and clarifying the data in the pipeline. The following reply during an interview with a client manager illustrates a point of view that was shared widely across the team members. The client manager describes the kind of discussion around opportunities that occurs in the conference calls.

Client manager: “....we got people on board and asked for their help. You know, 'here's what's coming, could you get to this guy? Is he the right guy, or who's the right guy?' You know, that kind of a thing."

Interviewer: "I imagine that there were lots of documents that were articulating the opportunity. Did you need to be looking at what each other had? And how did you, what kinds of tools...."

Client manager: "Just email. Email and conference calls."

Interviewer: "Were there times that people had different versions...?"

Client manager: "...never a problem."

The team focused their discussions around major opportunities and those that were about to close. For instance, in pipeline review meetings client managers might update the team on an opportunity, and then the general manager or others would chime in with a further update as to their dealings with a client related to the opportunity. Rather than focusing on how the data had changed in the CRM tool, the discussion revolved around the content of the client's interests and the strategy the team was employing on the effort.
In summary, the team which most closely embodied the Do-it-asYou-Like approach lacked a sense of being burdened by process. They were observed, at the same time, to be highly conversant on the major opportunities being pursued by their team members, reflecting a significant degree of awareness of the status. Their team communications and relationships were marked by few cantankerous interactions related to tracking down information needed to update the pipeline according to the terms set by the tool.

While we do not present arguments as to the relevance and accuracy of the pipeline data as gathered in either the Do-it-Alike or Do-it-as-You-Like approaches as related to broader corporate interests, it is important to note that in neither case did we uncover evidence of there being flawed, insufficient or incomplete pipeline data which resulted in measurable detrimental business impact. Indeed both of the teams representing the two approaches were considered high performing teams with strong business results. Our focus in this paper has been on understanding the relationship of these different approaches to pipeline management on team dynamics and organizational relations. Understanding that relational practices can affect collaborative effectiveness at the micro level, we are suggesting that how such tools and processes are taken up and used at the collective level within sales teams has an impact on organizational relations.

\section{DISCUSSION OF FINDINGS}

The Do-it-Alike and Do-it-as-You-Like approaches illustrate two ends of a continuum in how the enterprise-wide CRM tool and attendant processes were managed and experienced. Table 1 summarizes the differences between the two approaches across the five dimensions described earlier.

Table 1: Differences across the Do-it-Alike and Do-it-As-YouLike Approaches

\begin{tabular}{|c|c|c|}
\hline Dimension & Do-it-Alike & Do-it-As-You-Like \\
\hline $\begin{array}{l}\text { Recording } \\
\text { information }\end{array}$ & $\begin{array}{l}\text { Direct entry into } \\
\text { CRM by each } \\
\text { member }\end{array}$ & $\begin{array}{l}\text { Variable tools used per } \\
\text { individual preference }\end{array}$ \\
\hline $\begin{array}{l}\text { Roles \& } \\
\text { responsibilities } \\
\text { for managing } \\
\text { information }\end{array}$ & $\begin{array}{l}\text { - Each member } \\
\text { records to CRM } \\
\text { Sales team } \\
\text { assistant and/or } \\
\text { client managers } \\
\text { ensure info entry }\end{array}$ & $\begin{array}{l}\text { - Client managers } \\
\text { understand current } \\
\text { status } \\
\text { - Controller and } \\
\text { general manager } \\
\text { update tool }\end{array}$ \\
\hline $\begin{array}{l}\text { Dissemination of } \\
\text { information } \\
\text { within team }\end{array}$ & $\begin{array}{l}\text { - Access CRM } \\
\text { directly } \\
\text { - Reports from } \\
\text { CRM }\end{array}$ & $\begin{array}{l}\text { - Variable forms } \\
\text { - Mutually agreed } \\
\text { ways }\end{array}$ \\
\hline $\begin{array}{l}\text { Artifact used in } \\
\text { reviewing the } \\
\text { pipeline }\end{array}$ & $\begin{array}{l}\text { Report generated } \\
\text { by the CRM tool }\end{array}$ & $\begin{array}{l}\text { Opportunities } \\
\text { identified by members }\end{array}$ \\
\hline $\begin{array}{l}\text { Focus of the } \\
\text { pipeline reviews }\end{array}$ & $\begin{array}{l}\text { - Process } \\
\text { completion } \\
\text { Data } \\
\text { thoroughness } \\
\text { - Total view onto } \\
\text { existing } \\
\text { opportunities }\end{array}$ & $\begin{array}{l}\text { - Current actions } \\
\text { - Information relevant } \\
\text { to tactical \& strategic } \\
\text { plays } \\
\text { - Significant changes } \\
\text { to data }\end{array}$ \\
\hline
\end{tabular}


The Do-it-Alike approach requires that each member of the team engage directly with the tool and provide standardized pipeline information in the form required by the tool. As such each person has to master the tool and understand the meaning of the information entered into the tool by others. This is both time consuming and focuses attention on the process itself rather than the work which the process is meant to support. In addition, this approach results in some individuals (e.g., client managers, sales team assistants) needing to track others down to get their updates or to enter the update into the system themselves. During pipeline review meetings, much of the time is spent clarifying the meaning of the information entered into the tool's database and making necessary adjustments with less time spent on strategizing around major opportunities.

However, the highly coordinated fashion of the Do-it-Alike approach means that once data is entered in the system and discussed the potential for people both inside and outside the team to be able to refer to a single data source for a snapshot of the account exists. While lags do occur, the standardized tool provides a potential central repository for knowledge of opportunities on the account.

In contrast, team communications for those using the Do-it-asYou-Like approach about the pipeline is not mediated by the CRM tool but instead takes the form preferred by those involved. This results in a highly flexible approach that is does not require each member to interact with the tool. There is therefore no need to track people down for updates. In the end senior team management takes responsibility for ensuring the tool is updated as needed for other enterprise operations. As such, pipeline review meetings can be spent looking for ways to help advance the opportunities in play.

However, because only those additions, deletions or changes deemed of significance at the time of the meeting are discussed and because a report of the total view onto the account opportunities' status only loosely guides the meeting, changes in opportunities might not necessarily be known by all team members.

\section{Multiple approaches to the same end}

There are multiple approaches to integrating a standardized tool into team practices. We have shown that both the Do-it-Alike and the Do-it-as-You-Like approaches accomplish the task of managing the sales pipeline, and both result in the inputting of information to the CRM tool as required by the company. Moreover, different approaches can produce desirable business results, as evidenced by the fact that the two teams that exemplify these contrasting approaches were both considered high performing teams. What differs is the way that the tool intersects with information sharing configurations and strategies of the teams. Different approaches result in different outcomes in terms of how they support information exchange in the context of intrateam relations.

\section{Variable impact on information exchange}

Our examination of the practices of sales opportunity management reveals differences in the steps involved in translating pipeline information as it was passed up the reporting structure. In the Doit-Alike approach, information had to be interpreted both up and down the reporting structure (Figure 1). Each individual seller had to interpret and translate the current state of their sales opportunities as captured in the CRM tool in order to determine what specific information he or she needed to add or change. (e.g., why did this date or name change? Should I now split up this opportunity into several opportunities or keep as one?) When passed to the assistant, she then had to similarly first interpret and then translate the changes in the CRM database made by others before knowing what else needed updating (e.g., what does this number mean? Is it the least possible amount or most likely amount of sale? Is this opportunity the same as that one?). Further, the information had to be interpreted by sales managers and general managers during the weekly sales opportunity conference call. The standard view of the CRM tool did not allow for insight into those kinds of questions, so interpretation and translation had to occur at every level.

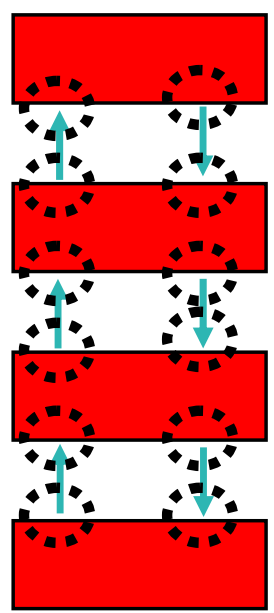

Figure 1. Do-it-Alike process for updating the CRM tool with interpretation and translation points circled

In contrast, our examination of the team mostly closely representing the Do-it-as-You-Like approach reveals that sales opportunity status information was interpreted and translated only by the party who would next pass it on (Figure 2). Sellers communicated sales opportunity status in a way that was personally chosen requiring no interpretation or translation by them. Those personally chosen representations of sales opportunity status were then passed to sales managers, who interpreted and translated that information and then communicated it on in a manner of their choosing. This occurred up the reporting structure until it reached the general manager and the operations assistant, who would then interpret and translate the information into the mandated CRM reporting tool.

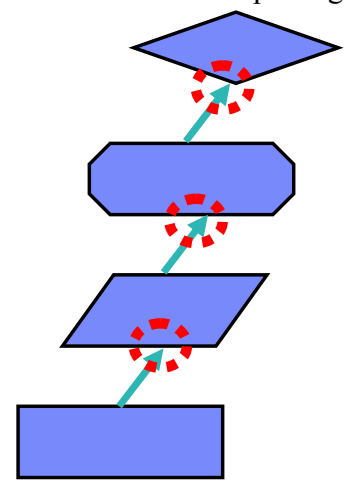

Figure 2. Do-it-as-You-Like approach to updating sales opportunity information with translation and interpretation points circled 
Standard tool use, coordination and organizational effectiveness

What does this examination suggest about the impact of standardized tools and processes on the coordination of sales team activities and operations? As stated earlier, a common view holds that standardized processes are the most effective way to engage with standardized tools. However, our findings reveal that standard information together with the use of standardized tools need not result in standardized processes. Both teams ultimately tracked sales opportunity status using the CRM tool, and both teams communicated standard information about opportunities (i.e., client name, potential revenue amount, anticipated close date, etc.). However, each team configured and coordinated to communicate and share information about opportunities in significantly different ways, resulting in very different outcomes in terms of team interactions, time spent focusing on the process, and time spent focusing on developing opportunities.

There is also a commonly held view that standardized information using a standardized tool coupled with a standard process will increase team efficiency. However, our findings suggest that this is not always the case. The Do-it-Alike team spent almost twice as much time updating sales opportunity status using the CRM tool than did the team mostly closely aligned with the Do-it-as-YouLike approach (124 estimated total hours vs. 65 estimated total hours). This difference has potentially significant implications for where the majority of sellers' efforts are focused (i.e., on managing the pipeline or on furthering sales) and for staffing models if scaled across other similar teams. ${ }^{3}$ Overall, our findings suggest that time spent on the pipeline process does not always contribute to furthering sales and in fact, complying with standard processes may reduce the time available for sales.

As described earlier, a technology's impact is shaped and mediated by the particular ways it's integrated into day to day practices. As a result, one can not anticipate in the design of a tool all the ways that it will be integrated into day-to-day practices [2, $3,10,12,19]$. However, one can expect that how standardized tools are integrated within team practices will most certainly have an impact on the way information is captured, recorded, entered into the system and disseminated and on who interacts with the system. These factors, in turn, will impact the working dynamics of the team. Actively thinking about and anticipating some of these outcomes during design and deployment can result in a more flexible tool that can support being integrated into team practices in different ways and minimize disruptions to team dynamics.

\section{CONCLUSIONS}

In this paper, we have explored how an enterprise-wide CRM tool used to track and manage information on sales opportunities gets taken up and is used among sales teams from a global IT firm. Our research interest has been to provide an in-depth

\footnotetext{
${ }^{3}$ For instance, if 15 similar teams follow the Do-it-Alike team's process, approximately 22.5 FTE weekly will be spent on updating sales opportunity status. This estimate assumes an average team size of 61 (per average size of teams of this kind). Key differences in time use between the teams were: number of minutes weekly per seller on the process; additional time required for client managers or other designated personnel to track, coordinate, translate and update information; and the $50 \%$ effort of the sales team assistant of the team compared to the much smaller degree of effort by the general manager and controller for the other team.
}

understanding of how the use of a standardized tool differs across teams and how these differences impact intra-team relations.

We identified two approaches that point to strikingly different uses of a standard CRM tool with significant consequences for team dynamics. We found that while both teams used the standardized tool, the way they integrated the tool into their information exchanges and pipeline strategies differed significantly. These differences yielded advantages and disadvantages, but from the perspective of organizational relations we found that allowing individual variability in how sales pipeline information was maintained and reported (i.e., the Do-it-as-YouLike approach) facilitated information exchange and enhanced meaningful interactions among team members. Conversely, when team members were required to report pipeline information using the standardized process and tool (i.e., the Do-it-Alike approach), they spent a significant amount of time interpreting existing data in the CRM database and focusing their interactions with others on tracking down and reconciling information more for the sake of process completion and less for purposes of advancing or otherwise strategizing around client sales opportunities.

Our findings caution about the risks of evaluating technology without understanding how the technology is enacted in practice. We conclude by summarizing three implications for organizational relations and exchange on how standardized tools and processes are designed, deployed and embedded into work practices. We substantiate these implications by drawing on the five key dimensions identified to differentiate the CRM tool use in the current case.

\section{Design tools and deployment strategies to allow flexible use} and application.

Our study showed that despite the mandated use of the standardized CRM tool, teams devised different ways of recording pipeline information and disseminating pipeline information within the team. In the Do-it-Alike case efforts were made to enforce a standard process, resulting in more time and energy spent on interpreting, translating, gathering and entering data. This not only occupied individuals' attention and time in the course of the week, but also consumed a high proportion of their attention during the weekly pipeline review meetings. At the same time, the nature of the interactions prompted by the process did not necessarily advance shared understanding and intra-team relations. Where there was greater flexibility, as in the Do-it-as-You-Like case, we saw no evidence of any negative affects on intra-team dynamics.

2. Consider variable implications of tool and process adoption on the division of labor

A comparison of the roles and responsibilities for managing pipeline information between the two approaches illustrates how standardized tools and processes are integrated into the collective work practices of sales teams has implications for how labor is configured and divided. In the Do-it-as-You-Like approach the general manager and controller update the CRM tool based on information supplied to them by team members. There was no need for someone to dedicate a large portion of their time making sure others input information into the tool or when all else failed do it themselves. In addition, client managers and others on the team were not cast in the role of 'the people chasing down information' for the weekly pipeline calls. The Do-it-Alike approach also required that each member of the team be "expert" enough to input their own data into what is known as a 
cumbersome tool to use, while this ability was only required by a couple of people on the team that had more of a Do-it-as-YouLike approach.

3. Understand that an excessive focus on tool use and process has consequences for the work overall

Sales professionals and sales teams have as their primary objective to support their clients by providing products and services that address business goals. The work of sales teams, ultimately, is selling. The deployment of tools and processes into that agenda has implications for definitions of the work itself. Our findings show that the artifacts used in reviewing the pipeline along with the focus of the pipeline review meetings reflected how oriented teams were to selling verses minding the demands of standardized tools and processes. The team characterized by the Do-it-Alike approach spent a great deal of their time making sure information in the tool was updated properly. Conversely the team with more of a Do-it-as-You-Like approach devoted little or no attention to the CRM tool during their pipeline review meeting, but instead interacted to advance selling opportunities.

This examination points to the ways in which information exchange acts as a vehicle for building, leveraging and deterring organizational relations. Information exchange is vital to the creation of shared understanding and disruptions can inhibit their creation. Further, interactions over the processes related to information exchange and over the meaning of the information can become enablers or detractors from the substantive matters of the work. These factors shape perceptions and experiences of team effectiveness and have consequences for the establishment and maintenance of organizational relations. It is not our intention to suggest that standardized tools and processes should not be used. Rather we are suggesting that designing and deploying tools that can be integrated into work practices more flexibly - with attention to divisions of labor and consideration for the impact of how tools will be used - can result in enhanced team dynamics.

\section{ACKNOWLEDGMENTS}

We would like to thank the sponsors of the research and the members of the global sales teams.

\section{REFERENCES}

1. Barley, Stephen R. Technology as an occasion for structuring: evidence from observations of CT scanners and the social order of radiology departments. Administrative Science Quarterly, 1986, 31:78-108.

2. Bentley, R. and Dourish, P. Medium versus Mechanism: Supporting Collaboration through Customisation. Proc. European Conf. Computer-Supported Cooperative Work ECSCW'95 (Stockholm, Sweden). Dordrecht: Kluwer, 1995.

3. Berente, N. and Youngjin, Y. Reconciliation Mechanisms and the Façade of Alignment with Enterprise Systems: the Case of NASA. Academy of Management Annual Meeting. Philadelphia, PA. 2007.

4. Blomberg, J. The Variable Impact of Computer Technologies on the Organization of Work Activities. In Computer-Supported Cooperative Work: A Book of Readings, I. Greif (ed.). Morgan Kaufman Publisher, San Mateo, California, 1988, 771-782.

5. Bowker, G. Star, S.L. Situations vs. standards in longterm, wide scale decision-making: the case of International
Classification of Diseases. Proceedings of the TwentyFourth Annual Hawaii International Conference on Systems Sciences, 1991.

6. Chalmeta, R. Methodology for customer relationship management. Journal of Systems and Software, 79 (2005), 1015-1024.

7. Dourish, P. Process Descriptions as Organisational Accounting Devices: The Dual Use of Workflow Technologies. Group'01 Conference Proceedings, Sept. 3Oct. 3, 2001. Boulder, CO, USA

8. Dourish, P., Lamping, J., Rodden, T. Building bridges: customization and mutual intelligibility in shared category management. Proceedings of the International ACM SIGGROUP Conference on Supporting Group Work, 1999.

9. Hayes, N. Boundless and Bounded Interactions in the Knowledge Work Process: The Role of Groupware Technologies. LUMS Working Paper, Lancaster University, http://www.lums.co.uk.publications.

10. Henderson, A., Kyng, M. There's no place like home: continuing design in use: Design at work: cooperative design of computer systems. Lawrence Erlbaum Associates, Inc, Mahwah, NJ, 1992, 219-240.

11. Hitt, L.M. and Brynjolfsson, E. Information technology and internal firm organization. Journal of Management Information Systems, 14 (1997), 81-202.

12. Kalling T. and Selander, L. Returns on ERP Investments. Managerial and Organizational Factors. Academy of Management Annual Meeting. Philadelphia, PA. 2007.

13. Malone, T.W. and Rockart, J.W. How will information technology reshape organizations?: Computers as coordination technology, in: Globalization, Technology, and Competition: The Fusion of Computers and Telecommunications in the 1990s, S.P. Bradley, J.A. Hausman and R.L. Nolan, eds., Harvard Business School Press, Boston, 1993, 37-55.

14. Orlikowski, W. J. Action and Artifact: The Structuring of Technologies-in-Use. Sloan Working Papers. 1995.

15. Orlikowski, W. J. Evolving with Notes: Organizational Change and Groupware Technology. Sloan Working Papers. 1995.

16. Orlikowski, W. J. Using Technology and Constituting Structures: A Practice Lens for Studying Technology in Organizations. Organization Science, 11, 4 (2000), 404428.

17. Standardization of European Marketing Programs and Process in the Consumer Electronics Industry: A Comparison Between Higher and Lower Performers. http://www.best-information.eu/international-marketingstrategies/index.html. Last accessed May 11, 2007.

18. Suchman, L. Blomberg, J. and Trigg, R. Reconstructing Technologies as Social Practice. American Behavioral Sciences. 43,3 (1999), 392-408.

19. Trigg, R. H., Bodker, S. From implementation to design: tailoring and the emergence of systematization in CSCW. Proceedings of the 1994 ACM conference on Computer Supported Cooperative Work, 1994.

20. Wladawsky-Berger, I. Business innovation in an On Demand World. Blog entry. http://irvingwb.typepad.com/blog/2005/09/index.html. Last accessed May 11, 2007. 